Brazilian Journal

of Chemical

ISSN 0104-6632

Printed in Brazil

Engineering

www.scielo.br/bjce

Vol. 35, No. 02, pp. 605 - 614, April - June, 2018

dx.doi.org/10.1590/0104-6632.20180352s20160654

(cc) BY

\title{
LIQUID-LIQUID EXTRACTION OF AROMATICS FROM HYDROCARBON MIXTURES IN CAPILLARIES
}

\author{
U. K. Arun Kumar ${ }^{1 *}$ and Ratan Mohan ${ }^{2}$ \\ ${ }^{1}$ Department of Chemical Engineering, Malaviya National Institute of Technology \\ Jaipur, J. L. N. Marg, Jaipur, Rajasthan-302017, India, Tel : +91-141-271-3513; \\ Mobile: +91-9549654174, E-mail address: ukakumar.chem@mnit.ac.in \\ ${ }^{2}$ Department of Chemical Engineering, Indian Institute of Technology Delhi, Hauz \\ Khas, New Delhi, Delhi 110016, India. Tel: +91-11-2659- 1033; \\ Email: ratan@iitd.ac.in
}

(Submitted: November 22, 2016; Revised: May 17, 2017; Accepted: May 31, 2017)

\begin{abstract}
An aromatics extraction study was conducted in capillaries of internal diameters in the range of 0.8 $\mathrm{mm}$ to $2 \mathrm{~mm}$. The systems chosen for study were ' $\mathrm{n}$-heptane + toluene + propylene carbonate', 'n-heptane + toluene + furfural' and 'synthetic naphtha reformate + (propylene carbonate + tetraethylene glycol)'. The aim of the work was to evaluate the feasibility of conducting aromatic separation in micro-capillaries and evaluate maximum efficiency. The results showed efficiencies ranging from $46.3 \%$ to $97.3 \%$, depending upon the combination of the flow velocity, residence time and channel diameter. The effect of individual parameters on extraction efficiency was also isolated from the various combinations. Efficiency increased from 68 to $83 \%$ as flow velocity increased from 0.11 to $0.96 \mathrm{~cm} / \mathrm{s}$, while residence time and channel diameter were fixed at 0.78 min and $2 \mathrm{~mm}$, respectively. The samples collected from the capillary quickly separated into clear liquid layers, indicating short settling times.
\end{abstract}

Keywords: aromatics separation, liquid-liquid extraction, micro-/milli-capillaries.

\section{INTRODUCTION}

Separation of aromatics from petroleum mixtures such as naphtha reformate, lube oils is part of petroleum refining and is done by liquid-liquid extraction in contactors like mixer-settler, sieve plate column, etc. Of late, the use of micro-channels for extraction is also being studied in view of process intensification possibilities. The small diameters of the channels provide high specific surface area in the range of $10,000-50,000 \mathrm{~m}^{2} / \mathrm{m}^{3}$, whereas the maximum surface area to volume ratio in stirred vessels is of the order of $1000 \mathrm{~m}^{2} / \mathrm{m}^{3}$ (Jovanovic et al., 2011; Antony et al., 2014). Other important advantage of using micro-channels is in mixing, where short diffusion distances enhance mass transfer ( $\mathrm{Su}$ et al., 2010). Further, micro-channel contacting provides better control and does not involve any mechanical moving parts for mixing. Various liquid-liquid flow patterns can be generated in micro-channels, namely: (a) drop flow, (b) slug flow (c) slug drop flow (d) deformed interface flow (e) annular and parallel flow (f) slug-dispersed flow and (g) dispersed flow (Kashid et al., 2011). But the most widely studied flow patterns for mass transfer applications are slug flow, drop flow and parallel flow. Amongst them, slug flow and emulsion flow are found to be more efficient for mass transfer. However, slug flow is more advantageous

" Corresponding author: Tel : +91-141-271-3513. Mobile: +91-954-965-4174, E-mail address: ukakumar.chem@mnit.ac.in 
than emulsion flow in terms of handling and settling time (Okubo et al., 2008; Kamio et al., 2011). Though several extraction studies involving two immiscible liquids in microchannels are seen in the literature, work related to aromatics extraction is reported here.

Burns and Ramshaw (2001) studied the extraction of acetic acid from kerosene using water as the solvent in a glass-chip channel employing the slug flow method. They obtained an extraction efficiency of $97 \%$. Kashid et al. (2007) carried out liquid-liquid extraction studies for three non-reactive systems using slug flow in microchannels. The three systems were 'water + iodine + kerosene', 'kerosene + acetic acid + water' and 'water + succinic acid $+n$-butanol'. Solutes were iodine, acetic acid and succinic acid, respectively. Extraction efficiencies of $90 \%$ were achieved for all the systems. Zhao et al. (2007) have reported extraction studies for the system 'water + succinic acid + n-butanol' in rectangular stainless steel microchannels with a T-junction and found that the mass transfer coefficient was three to four times higher than in the conventional contactors. Okubo et al. (2008) carried out extraction studies in microchannels employing three flow regimes, stratified, slug and emulsion flow, to extract phenol from dodecane using water as the solvent. They found that, for high throughput operations, the slug flow method of extraction was more suitable than the other two methods. Kamio et al. (2011) studied the separation of the ethyl ester of docosahexanoic acid (DHA-Et) with silver ions using slug flow and water-in-oil (W/O) emulsion methods. They too found that slug flow was more advantageous for easy handling and rapid extraction than the emulsion method. More recent studies on mass transfer and extraction in liquid-liquid slug flow in micro and small scale channels have been made by Assmann et al. (2011), Xu et al. (2013), Liu et al. (2014), Tsaoulidis and Angeli (2015).

In summary, though several studies of extraction in microchannels have been reported earlier, work on aromatic separation from hydrocarbon mixtures is not seen. Hence in the present work, solvent extraction of aromatics from hydrocarbon mixtures in microchannels is studied. The solvents employed were furfural, and a mix of propylene carbonate (PC) and tetra-ethylene glycol (TTEG), i.e., from the green solvents category. Two ternary systems, ' $n$-heptane+toluene+PC' and 'n-heptane+toluene+furfural', and one tencomponent 'synthetic naphtha reformate+PC+TTEG' were studied. Studies were conducted in micro-/ millichannels, actually capillaries, for three 'alkane + aromatic + solvent systems. The capillaries were of internal diameters (i.d.) from $0.8 \mathrm{~mm}$ to $2 \mathrm{~mm}$ and of varying lengths. Experiments were conducted for different flow rates and residence times. Effects of velocity, residence time and diameter on extraction efficiency were studied.

\section{EXPERIMENTAL METHODS}

\section{Materials}

Experiments were carried out in glass capillaries of i.d. $0.8 \mathrm{~mm}, 1.6 \mathrm{~mm}$ and $2 \mathrm{~mm}$. A Teflon i.e., polytetrafluoro ethylene (PTFE) capillary tubing of $1 \mathrm{~mm}$ i.d. was also used. The capillary lengths were in the range $5 \mathrm{~cm}$ to $45.7 \mathrm{~cm}$. Two syringe pumps (Harvard Apparatus) with an accuracy of $\pm 0.5 \%$ were employed for pumping the liquids through the capillaries.

The chemicals used in the study were n-heptane, toluene and cyclohexane (supplied by Qualigens, India) and benzene (supplied by Ranbaxy Fine Chemicals, India). All were HPLC grade materials. Furfural was supplied by $\mathrm{CDH}$ Laboratories, India. Dodecane and ethylbenzene were supplied by Spectrochem, India. o-Xylene was supplied by Loba Chemie, India. Propylene carbonate and tetra-ethylene glycol were from Sigma-Aldrich. The purities of all these chemicals were rated to be $>99 \%$ by the manufacturers. The materials were used as supplied by the manufacturers, without any further purification.

\section{Procedure}

The experimental setup for the microchannel extraction is shown schematically in Figure 1. It consists of two syringe pumps, silicone tubing and the capillary where extraction takes place. The capillary, shown by a dark solid line, is placed over a light source. A beaker placed at the end of the capillary collects the liquids that come out. An enlarged view of the capillary containing the liquid slugs is also shown. One end of the capillary is connected to the syringe pump by a silicone tube, through which the liquid solvent flows in. The tubing from the other syringe pump has a needle that pierces the first silicone tube such that the needle tip lies at the entrance of the capillary. The hydrocarbon feed mixture flows through the needle. Both the liquids meet each other at the entrance of the capillary and form slugs. After steady state was established, samples were collected from the open end of the capillary. The samples from both the raffinate and the extract layers from the collection flask were analyzed by gas chromatography to measure the composition. Experiments were repeated 
2-3 times to confirm the reproducibility of results. The conditions maintained in gas chromatography are given in Table 1 for the ternary systems and in Table 2 for the synthetic naphtha reformate system. For the ten component synthetic naphtha reformate system, most of the parameters were the same, except the injector and detector temperatures, which were lower by $25 \mathrm{~K}$, and the column final temperature, which was higher by $35 \mathrm{~K}$.

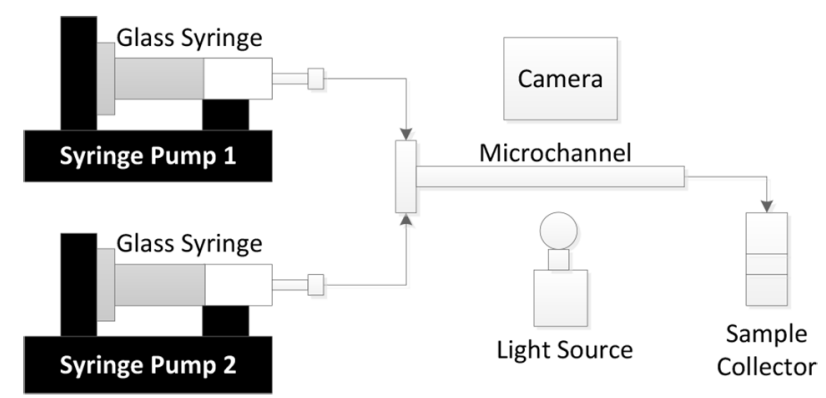

Figure 1. Schematic diagram of the microchannel extraction set-up.

\section{RESULTS AND DISCUSSION}

As stated earlier, the aim was to determine the effectiveness of using micro-channels or capillaries for aromatics extraction. For this, extraction efficiency has been taken as the measure and its variation with parameters like flow velocities, capillary diameter, residence time, have been studied. Subsequently, volumetric mass transfer coefficients were also estimated. The systems studied are 'n-heptane + toluene + propylene carbonate', 'n-heptane + toluene + furfural' and 'synthetic naphtha reformate + (propylene carbonate + tetraethylene glycol)'. Flow rates and capillary dimensions are given in Table 3 . The values were chosen such that effects of individual parameters like flow velocity, residence time, can also be isolated.

\section{Extraction efficiency}

Extraction efficiency is defined and calculated from Eqn. (1) (Zhao et al., 2007; Tang et al., 2013):

$$
E=\frac{C_{2, \text { out }}-C_{2, \text { in }}}{C_{2, \text { sat }}-C_{2, \text { in }}}
$$

In the equation, $C_{2, \text { in }}$ and $C_{2, \text { out }}$ represent the inlet and the outlet concentration of the solute (toluene for the ternary system and total aromatics in synthetic naphtha reformate) in the solvent respectively. $C_{2 \text { sat }}$ is the equilibrium concentration of the solute in the extract phase. E, is defined as the transported solute to the maximum transferable solute.
n-Heptane + Toluene + Propylene Carbonate at $25^{\circ} \mathrm{C}$

The extraction efficiency results for the system 'n-heptane + toluene + propylene carbonate' at $25^{\circ} \mathrm{C}$ are given in Table 4 . The table also gives the total volumetric flow rates and the corresponding residence times and velocities of the system. LLE data for this system were directly used from the report published by Salem (1993). Comparison of extract phase compositions with LLE tie line data is shown in Figure 2 for a $1 \mathrm{~mm}$ PTFE channel and $0.2 \mathrm{~mL} / \mathrm{min}$ flow rate. It can be seen that, for this case, the separation obtained in micro-channel extraction is almost the same as equilibrium separation. An extraction efficiency plot for the system in Figure 3 shows its variation with flow rate.

For a total volumetric flow rate of $0.2 \mathrm{~mL} / \mathrm{min}$ in a PTFE channel of $1 \mathrm{~mm}$ i.d. and $45 \mathrm{~cm}$ in length, an extraction efficiency of $97.3 \%$ was achieved in 1.79 min contact time. The high extraction efficiency is attributed to very good mass transfer between the slugs, due to the internal circulations that arise within them. As the flow rate is increased, the shearing of slugs also increases, leading to enhanced internal circulation. However, it was seen that at a flow rate of $0.8 \mathrm{~mL} / \mathrm{min}$, the extraction efficiency is lower, $87.8 \%$. This is because, although the velocity, $v$, is four times higher $(1.69 \mathrm{~cm} / \mathrm{s})$, the residence time, $\tau$, is now four times less at $0.45 \mathrm{~min}$. While the higher flow increases the internal circulations, it also decreases the contact time and reduces the extraction achieved. Thus, it is seen in Figure 3 that, while E generally decreases with flow rate $\mathrm{Q}$, this is the result of two opposing factors. Therefore, the particular combinations were taken from Table 4, which allow the effect of a single parameter to be isolated. This is discussed in the following.

\section{Effect of individual parameters}

The effect of flow velocity on extraction efficiency, keeping the diameter and the residence time constant, is shown in Figure 4(a). The channel diameter was 2 $\mathrm{mm}$ and the residence time was kept at $\sim 0.78 \mathrm{~min}$ by having channels of different lengths. Flow rates were varied from 0.2 to $1.8 \mathrm{~mL} / \mathrm{min}$, i.e., velocities of 0.109 to $0.955 \mathrm{~cm} / \mathrm{s}$. It is seen that the extraction efficiency increases from 67.9 to $82.9 \%$ as the velocity increases, i.e., now only this is the cause of improved internal circulation and mixing.

Likewise, the effect of residence time on extraction efficiency is shown in Figure 4(b). Residence time was changed by adjusting the capillary lengths and the flow rates. Here, the diameter of the channel and 
Table 1. GC parameters for the ternary systems.

\begin{tabular}{lc}
\hline Gas Chromatography & ULTIMA 2100 by NETEL \\
\hline Column & $10 \%$ OV-17 Chrom WHP $(2 \mathrm{~m} \mathrm{X} 1 / 800 ”)$ \\
Carrier Gas & Nitrogen at $5 \mathrm{~kg} / \mathrm{cm}^{2}$ \\
Fuel & Hydrogen at $4 \mathrm{~kg} / \mathrm{cm}^{2}$ \\
Air & Zero Air at $3 \mathrm{~kg} / \mathrm{cm}^{2}$ \\
Detector & Flame Ionization Detector \\
Detector Temperature & $568.15 \mathrm{~K}$ \\
Injector Temperature & $548.15 \mathrm{~K}$ \\
Flow Rate & $23 \mathrm{~mL} / \mathrm{min}$ \\
Column Temperature & Programmed \\
Initial temperature & $333.15 \mathrm{~K}($ iso=1 min) \\
Final Temperature & $498.15 \mathrm{~K}$ \\
Heating rate & $20 \mathrm{~K} / \mathrm{min}$ \\
\hline
\end{tabular}

Table 2. GC parameters for the 'synthetic naphtha reformate +PC +TTEG' system.

\begin{tabular}{lc}
\hline Gas Chromatography & ULTIMA 2100 by NETEL \\
\hline Column & $10 \%$ OV-17 Chrom WHP $\left(2 \mathrm{~m} \mathrm{X} 1 / 800^{\prime \prime}\right)$ \\
Carrier Gas & Nitrogen at $5 \mathrm{~kg} / \mathrm{cm}^{2}$ \\
Fuel & Hydrogen at $4 \mathrm{~kg} / \mathrm{cm}^{2}$ \\
Air & Zero Air at $3 \mathrm{~kg} / \mathrm{cm}^{2}$ \\
Detector & Flame Ionization Detector \\
Injector Temperature & $523.15 \mathrm{~K}$ \\
Detector Temperature & $543.15 \mathrm{~K}$ \\
Flow Rate & $25 \mathrm{~mL} / \mathrm{min}$ \\
Column Temperature & Programmed \\
Step 1 & $333.15 \mathrm{~K}($ iso $=6 \mathrm{~min})$ \\
Initial temperature & $383.15 \mathrm{~K}$ \\
Final Temperature & $8 \mathrm{~K} / \mathrm{min}$ \\
Heating rate & \\
Step 2 & $383.15 \mathrm{~K}$ \\
Initial temperature & $533.15 \mathrm{~K}$ \\
Final Temperature & $22 \mathrm{~K} / \mathrm{min}$ \\
Heating rate & \\
\hline
\end{tabular}

the velocity of the fluids are held constant. For the diameter (i.d.) of $2 \mathrm{~mm}$ and velocity fixed at $0.64 \mathrm{~cm} / \mathrm{s}$, it was found that the extraction efficiency increased from 52.7 to $81.7 \%$, corresponding to a residence time increase from 0.26 to $0.78 \mathrm{~min}$.

Finally the effect of varying the diameter of the channel on extraction efficiency was also found. The results shown in Figure 4(c) have a residence time of $\sim 0.78 \mathrm{~min}$ and the velocity fixed at $0.65 \mathrm{~cm} / \mathrm{s}$. Extraction efficiency decreased with the increase in diameter, from 95.7 to $81.7 \%$.

\section{n-Heptane+Toluene+Furfural and Synthetic Naph- tha Reformate $+(P C+T T E G)$ at $30^{\circ} \mathrm{C}$}

In these two systems studied, toluene was extracted by the solvent furfural in the first case. In the second, total aromatics were extracted from synthetic naphtha reformate (a mixture containing n-hexane, n-octane, n-dodecane, cyclohexane, benzene, toluene, o-xylene and ethylbenzene). Propylene carbonate (PC) mixed with $20 \%$ tetraethylene glycol (TTEG) was used as solvent. The percentage of co-solvent TTEG was chosen arbitrarily. PC has reasonable capacity but low selectivity (Salem, 1993). On the other hand, TTEG has high selectivity but low capacity (Saha, 1998). In order to increase the selectivity of propylene carbonate, tetraethylene glycol was chosen, which was envisaged to increase the selectivity. In addition, TTEG is reported to be superior to other glycols, mono, di, tri- ethylene glycols (Somekh and Friedlander, 1970). Experiments were conducted in all the three channels. The extraction efficiency results for different channels 
Table 3. Capillary dimensions and flowrates employed in the experiments.

\begin{tabular}{|c|c|c|c|c|c|}
\hline Channel & Length & Area & Volume & Total flow rate & Residence time \\
\hline \multirow[t]{2}{*}{ (i.d.) } & $\mathrm{cm}$ & $\mathrm{cm}^{2}$ & $\mathrm{~cm}^{3}$ & $\mathrm{~cm}^{3} / \mathrm{min}$ & $\min$ \\
\hline & & & & 0.2 & 1.795 \\
\hline \multirow[t]{2}{*}{$1 \mathrm{~mm}$ PTFE } & 45.7 & 0.00785 & 0.3591 & 0.4 & 0.898 \\
\hline & & & & 0.8 & 0.449 \\
\hline \multirow[t]{3}{*}{$0.8 \mathrm{~mm}$ glass } & 30.5 & 0.00502 & 0.1532 & 0.2 & 0.766 \\
\hline & & & & 0.4 & 0.383 \\
\hline & & & & 0.8 & 0.192 \\
\hline $1.6 \mathrm{~mm}$ glass & 30.5 & 0.03142 & 0.6132 & 0.77 & 0.786 \\
\hline \multirow[t]{3}{*}{$2 \mathrm{~mm}$ glass } & 5 & 0.03142 & 0.1571 & 0.2 & 0.763 \\
\hline & & & & 0.4 & 0.387 \\
\hline & & & & 0.8 & 0.195 \\
\hline \multirow[t]{2}{*}{$2 \mathrm{~mm}$ glass } & 10 & 0.03142 & 0.3142 & 0.4 & 0.785 \\
\hline & & & & 1.2 & 0.262 \\
\hline \multirow[t]{2}{*}{$2 \mathrm{~mm}$ glass } & 20 & 0.03142 & 0.6283 & 0.8 & 0.785 \\
\hline & & & & 1.2 & 0.524 \\
\hline $2 \mathrm{~mm}$ glass & 30.5 & 0.03142 & 0.9582 & 1.2 & 0.785 \\
\hline \multirow[t]{3}{*}{$2 \mathrm{~mm}$ glass } & 45.7 & 0.03142 & 1.4363 & 0.2 & 7.182 \\
\hline & & & & 0.4 & 3.591 \\
\hline & & & & 0.8 & 1.795 \\
\hline
\end{tabular}

Table 4. Extraction efficiency results for the system n-Heptane + Toluene + Propylene Carbonate at $25^{\circ} \mathrm{C}$.

\begin{tabular}{|c|c|c|c|c|c|}
\hline Channel & Length & Total flow rate & Residence time & Velocity & Extraction Efficiency \\
\hline & $\mathrm{cm}$ & $\mathrm{cm}^{3} / \mathrm{min}$ & $\min$ & $\mathrm{cm} / \mathrm{s}$ & $\%$ \\
\hline \multirow{3}{*}{$1 \mathrm{~mm}$ PTFE } & \multirow{3}{*}{45.7} & 0.2 & 1.795 & 0.42 & 97.3 \\
\hline & & 0.4 & 0.898 & 0.84 & 91.0 \\
\hline & & 0.8 & 0.449 & 1.69 & 87.8 \\
\hline \multirow{3}{*}{$0.8 \mathrm{~mm}$ glass } & \multirow{3}{*}{30.5} & 0.2 & 0.766 & 0.66 & 95.7 \\
\hline & & 0.4 & 0.383 & 1.32 & 91.5 \\
\hline & & 0.8 & 0.192 & 2.65 & 88.3 \\
\hline $1.6 \mathrm{~mm}$ glass & 30.5 & 0.77 & 0.786 & 0.647 & 84.2 \\
\hline \multirow{3}{*}{$2 \mathrm{~mm}$ glass } & \multirow{3}{*}{5} & 0.2 & 0.763 & 0.10 & 67.9 \\
\hline & & 0.4 & 0.387 & 0.21 & 58.4 \\
\hline & & 0.8 & 0.195 & 0.43 & 46.3 \\
\hline \multirow[t]{2}{*}{$2 \mathrm{~mm}$ glass } & \multirow[t]{2}{*}{10} & 0.4 & 0.785 & 0.21 & 73.8 \\
\hline & & 1.2 & 0.262 & 0.64 & 52.7 \\
\hline \multirow[t]{2}{*}{$2 \mathrm{~mm}$ glass } & \multirow[t]{2}{*}{20} & 0.8 & 0.785 & 0.42 & 79.8 \\
\hline & & 1.2 & 0.524 & 0.64 & 75.5 \\
\hline $2 \mathrm{~mm}$ glass & 30.5 & 1.2 & 0.785 & 0.64 & 81.7 \\
\hline \multirow{4}{*}{$2 \mathrm{~mm}$ glass } & \multirow{4}{*}{45.7} & 0.2 & 7.182 & 0.10 & 90.6 \\
\hline & & 0.4 & 3.591 & 0.21 & 87.6 \\
\hline & & 0.8 & 1.795 & 0.42 & 85.5 \\
\hline & & 1.8 & 0.785 & 0.95 & 82.9 \\
\hline
\end{tabular}




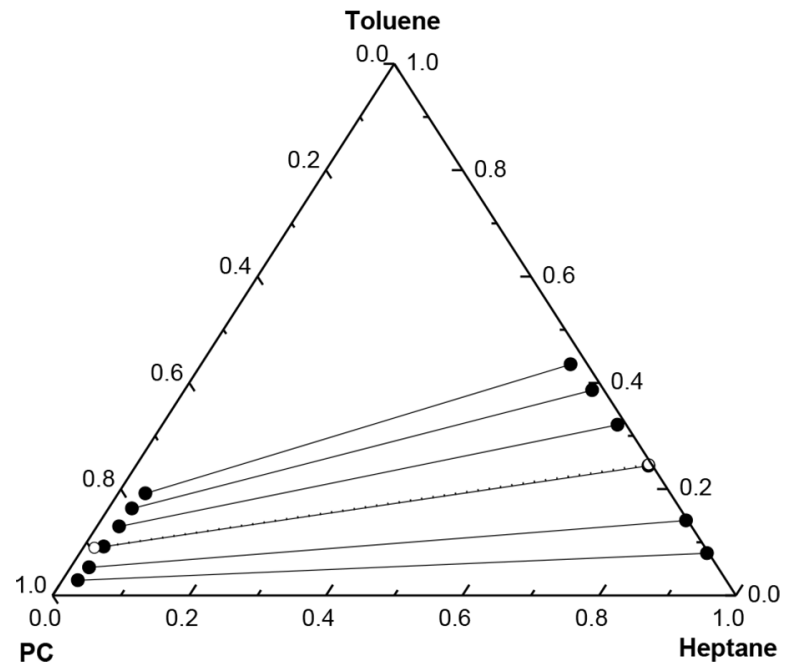

Figure 2. Comparison of equilibrium and extraction data for the system "n-heptane (1) + toluene (2) + PC (3)" at $298.15 \mathrm{~K}$; (•) LLE, Salem et al. (1993), (०) $1 \mathrm{~mm}$ PTFE channel, flow rate $0.2 \mathrm{ml} / \mathrm{min}$.

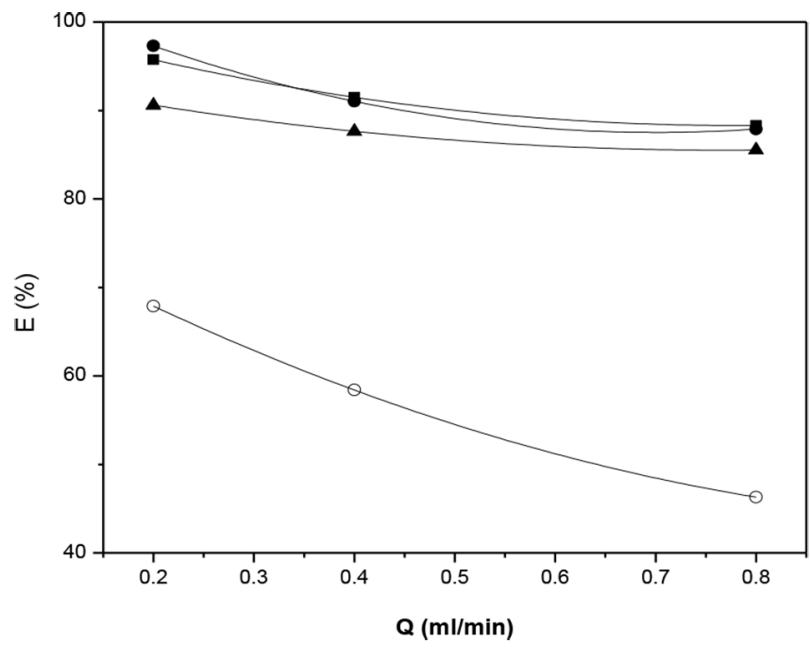

Figure 3. Extraction efficiency, E, for the system 'n-heptane + toluene $+\mathrm{PC}^{\prime}$ at $298.15 \mathrm{~K} ;(\bullet) 1 \mathrm{~mm}$ channel- $45 \mathrm{~cm},(\bullet) 0.8 \mathrm{~mm}$ channel-30

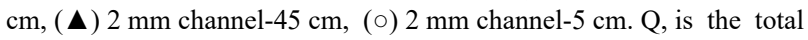
volumetric flow rate.

and flow rates are shown in Tables 5 and 6 respectively for the above systems. Plots showing extraction efficiency variation with flow rates are also given in Figure 5(a) and (b).

Although for these two systems there are not sufficient number of combinations of flow rate and capillary dimensions to show individual parameter effects as distinctly as in Figure. 4(a)-(c), trends similar to that observed for the system 'n-heptane + toluene + PC' are clear. Thus, it may be seen in Table 3 that, with a $0.8 \mathrm{~mm}$ glass capillary, even when $\tau$ and

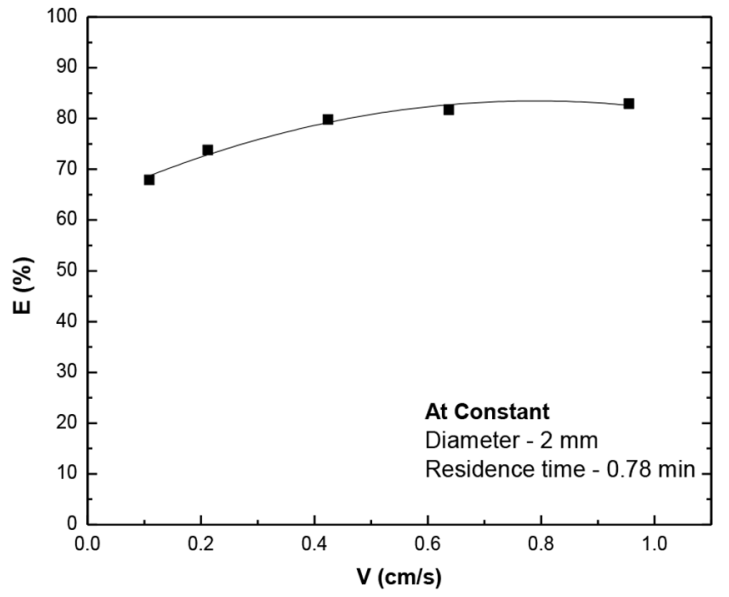

(a)

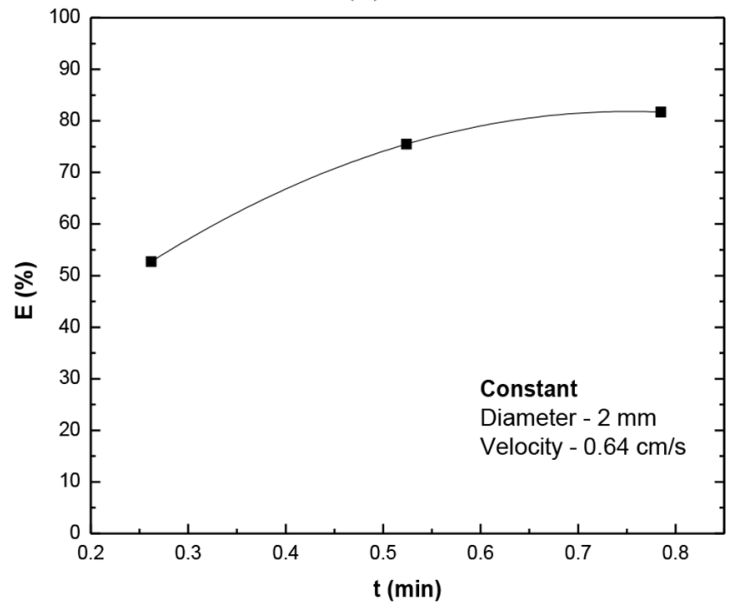

(b)

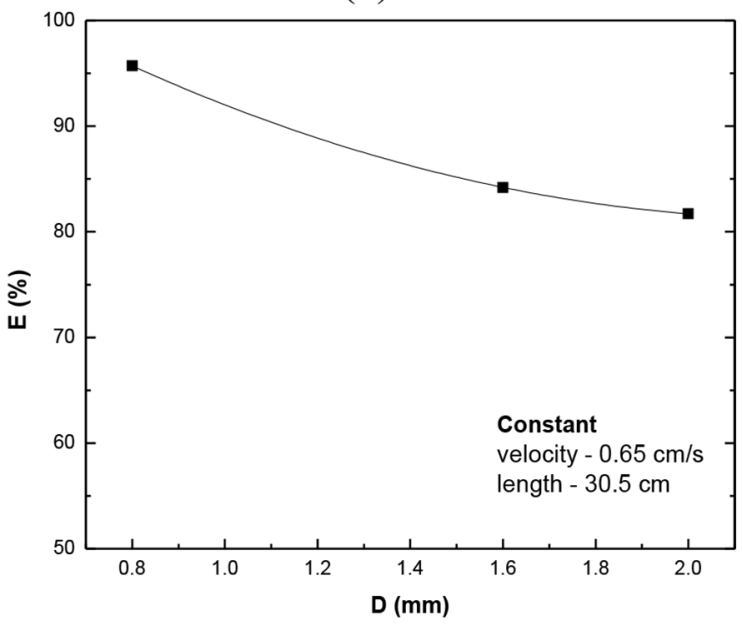

(c)

Figure 4. Results for the system 'n-heptane + toluene $+\mathrm{PC}^{\prime}$ at $298.15 \mathrm{~K}$. (a) Effect of velocity on efficiency at constant diameter and residence time. (b) Effect of residence time on efficiency at constant diameter and velocity. (c) Effect of diameter on efficiency at constant velocity and residence time. 
Table 5. Extraction efficiency results for the system n-heptane + toluene + furfural at $30^{\circ} \mathrm{C}$.

\begin{tabular}{|c|c|c|c|c|c|}
\hline Channel & Length & Total flow rate & Residence time & Velocity & Extraction Efficiency \\
\hline & $\mathrm{cm}$ & $\mathrm{cm}^{3} / \mathrm{min}$ & $\min$ & $\mathrm{cm} / \mathrm{s}$ & $\%$ \\
\hline \multirow{3}{*}{$0.8 \mathrm{~mm}$ glass } & \multirow{3}{*}{30.5} & 0.2 & 0.766 & 0.66 & 90.9 \\
\hline & & 0.4 & 0.383 & 1.32 & 87.5 \\
\hline & & 0.8 & 0.192 & 2.65 & 85.1 \\
\hline \multirow{3}{*}{$1 \mathrm{~mm}$ PTFE } & \multirow{3}{*}{45.7} & 0.2 & 1.795 & 0.42 & 96.7 \\
\hline & & 0.4 & 0.898 & 0.84 & 89.7 \\
\hline & & 0.8 & 0.449 & 1.69 & 86.1 \\
\hline
\end{tabular}

Table 6. Extraction efficiencies for the system synthetic naphtha reformate $+(\mathrm{PC}+\mathrm{TTEG} 20 \%)$ at $30^{\circ} \mathrm{C}$.

\begin{tabular}{|c|c|c|c|c|c|}
\hline Channel & Length & Total flow rate & Residence time & Velocity & Extraction Efficiency \\
\hline i.d. & $\mathrm{cm}$ & $\mathrm{cm}^{3} / \mathrm{min}$ & $\min$ & $\mathrm{cm} / \mathrm{s}$ & $\%$ \\
\hline \multirow{3}{*}{$0.8 \mathrm{~mm}$ glass } & \multirow{3}{*}{30.5} & 0.2 & 0.766 & 0.66 & 93.3 \\
\hline & & 0.4 & 0.383 & 1.32 & 90.4 \\
\hline & & 0.8 & 0.192 & 2.65 & 89.2 \\
\hline \multirow{3}{*}{$1 \mathrm{~mm}$ PTFE } & \multirow{3}{*}{45.7} & 0.2 & 1.795 & 0.42 & 96.8 \\
\hline & & 0.4 & 0.898 & 0.84 & 94.4 \\
\hline & & 0.8 & 0.449 & 1.69 & 87.9 \\
\hline \multirow{3}{*}{$2 \mathrm{~mm}$ glass } & \multirow{3}{*}{45.7} & 0.2 & 7.182 & 0.10 & 86.7 \\
\hline & & 0.4 & 3.591 & 0.21 & 84.4 \\
\hline & & 0.8 & 1.795 & 0.42 & 81.9 \\
\hline
\end{tabular}

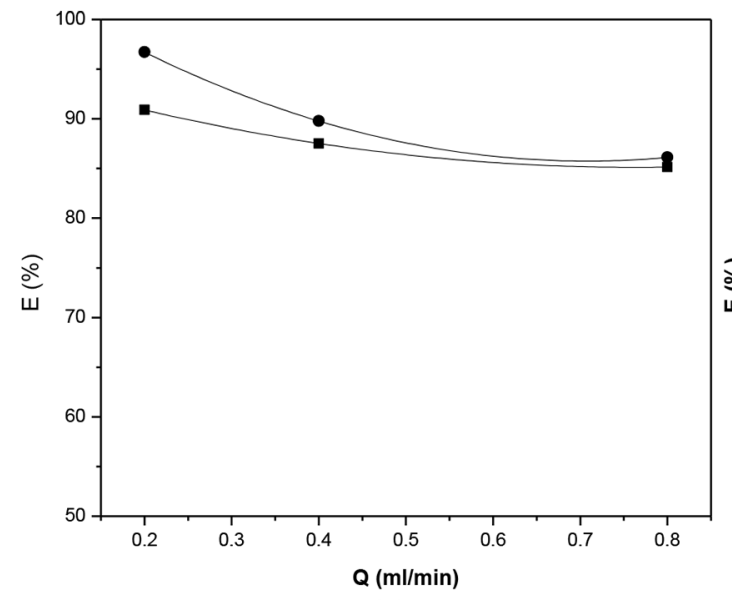

(a)

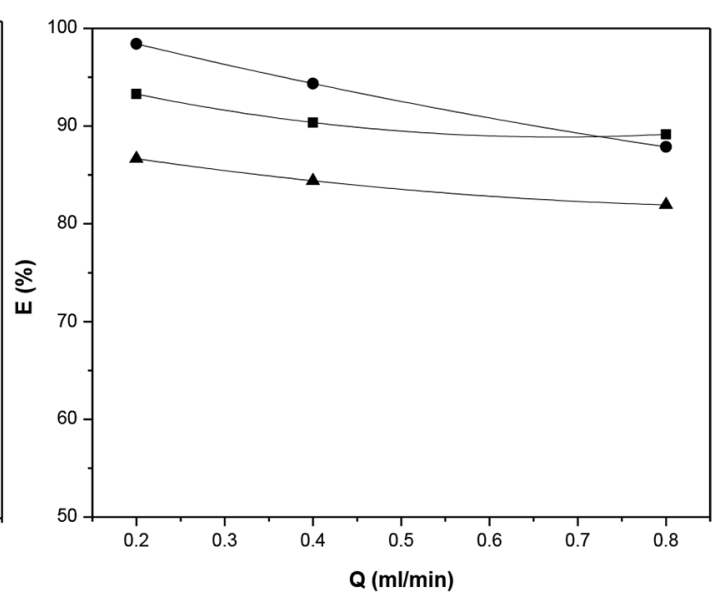

(b)

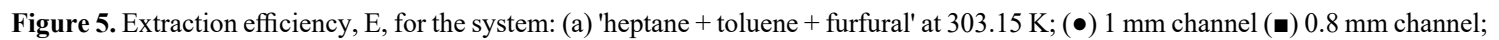

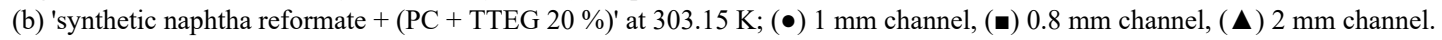

$v$ are smaller $(0.383 \mathrm{~min}$ and $1.32 \mathrm{~cm} / \mathrm{s})$ the extraction efficiency is higher $(87.5 \%)$ than $86.1 \%$ obtained in the $1 \mathrm{~mm}$ PTFE case when $\tau$ and $v$ are both greater: $0.449 \mathrm{~min}$ and $1.69 \mathrm{~cm} / \mathrm{s}$. The smaller diameter effect causing more shear and mixing is seen here. Of course, in this case the lower wetting characteristics of PTFE may be adding further to a lower shear. A very similar result is seen in Table 4, too where $\mathrm{E}=90.4 \%$ for a 0.8 $\mathrm{mm}$ glass capillary versus $\mathrm{E}=87.9 \%$ for $1 \mathrm{~mm}$ PTFE, $\tau$ and $v$ being the same. On the other hand (again in Table 4), for the same $\tau(=1.785 \mathrm{~min})$ and $v(=0.42$ $\mathrm{cm} / \mathrm{s}) 1 \mathrm{~mm}$ PTFE gives $\mathrm{E}=96.8 \%$ compared to $\mathrm{E}=$ $81.9 \%$ for a $2 \mathrm{~mm}$ glass capillary. Clearly the increase in diameter is now too much (the double) making the glass capillary perform poorer.

It was also noted that, for the ' $n$-Heptane + Toluene+ Furfural' system in PTFE tubing, the hydrocarbon mixture formed the continuous phase and the solvent 
furfural formed the slugs. Thus, the hydrocarbon mixture wets the PTFE material surface more. On the other hand, in the $0.8 \mathrm{~mm}$ glass capillary, furfural formed a continuous layer and the hydrocarbon mixture was dispersed as slugs. However, it is seen that this flow inversion does not affect the basic variation of E vs Q (Figure.3). Extraction was conducted for this system in only these two channels as slug flow was not formed in the $2 \mathrm{~mm}$ channel. In contrast the system formed a stratified flow in the $2 \mathrm{~mm}$ channel.

The high efficiencies suggest that micro channels can be used for liquid-liquid extraction to achieve a high degree of separation in small channels, reducing the size of the equipment required to achieve the same efficiency. Overall the extraction efficiencies were seen to be above $80 \%$ and as high as $97 \%$. Some low values were also observed, $46.3 \%, 52.7 \%$, according to the operating parameters especially if the residence time is less. E values seen in earlier studies are 40 - 95 $\%$ (Kaske et al., 2016), 15 - $95 \%$ (Liu et al., 2014), 30 - $95 \%$ (Kashid et al., 2007) and 75 - $95 \%$ (Kurt et al., 2016), the variation again being due to system and operating parameter differences. It appears that mass transfer is not a major issue in the microchannel case. On the other hand, the two phases already separate as two slugs in the channel, and are seen to separate into two layers very quickly in the collection beaker. In the regular mixer-settler process the separation of the emulsion into two distinct phases takes much longer.

\section{Volumetric mass transfer coefficient}

Volumetric mass transfer coefficients $\left(\mathrm{k}_{\mathrm{L}} \mathrm{a}\right)$ were also determined. $\mathrm{k}_{\mathrm{L}}$ a values were obtained using the equation (2) (Kashid et al., 2011).

$$
k_{L} a=\frac{1}{\tau} \iota n\left(\frac{C_{2, \text { sat }}-C_{2, \text { in }}}{C_{2, \text { sat }}-C_{2, \text { out }}}\right)
$$

In the equation $\tau$ is the residence time and $C_{2}{ }{ }_{\mathrm{in}}$, $C_{2}$,out,$C_{2}$,sat are the inlet, outlet and equilibrium concentrations of the solute, as before in equation (1).

The variation of $\mathrm{k}_{\mathrm{L}}$ a values with volumetric flowrate is shown in Fig. 6(a) for the "n-heptane + toluene + PC' system. Figures 6(b) and 6(c) give similar results for the systems ' $n$-heptane + toluene + furfural' and 'synthetic naphtha reformate mixture' respectively. Figure. 6(a) shows that, for a $0.8 \mathrm{~mm}$ glass capillary, the $\mathrm{k}_{\mathrm{L}}$ a values are in the range 0.07 to $0.19 \mathrm{~s}^{-1}$, for 1 $\mathrm{mm}$ PTFE the range is 0.03 to 0.08 , and for a $2 \mathrm{~mm}$ glass capillary it is in the range 0.01 to 0.02 . It can be seen that the volumetric mass transfer coefficient increases with an increase in total volumetric flow rate. On the other hand, it decreases with an increase in the capillary diameter. Thus, $\mathrm{k}_{\mathrm{L}} \mathrm{a}$ values are higher for the $0.8 \mathrm{~mm}$ glass capillary than for the $1 \mathrm{~mm}$ PTFE capillary, which in turn are higher than those for the 2 $\mathrm{mm}$ glass capillary.

The volumetric mass transfer coefficients obtained in the present study ranged from 0.005 to $0.20 \mathrm{~s}^{-1}$ for the three systems studied. These are similar (slightly lower) in magnitude to the $\mathrm{k}_{\mathrm{L}}$ a values - 0.02 to 0.30 $\mathrm{s}^{-1}$ - reported by Kashid et al.(2011), for the system 'water + succinic acid + n-butanol' and 0.13 to $0.98 \mathrm{~s}^{-1}$ for 'water + iodine + kerosene'. Other values are 0.2 to $0.5 \mathrm{~s}^{-1}$ (Dessimoz et al., 2008), 0.01 to $0.33 \mathrm{~s}^{-1}(\mathrm{Xu}$ et al., 2013), 0.72 to $8.44 \mathrm{~s}^{-1}$ (Raimondi et al., 2014) 0.07 to $8.83 \mathrm{~s}^{-1}$ (Woitalka et al., 2014), 0.1 to $0.30 \mathrm{~s}^{-1}$ (Kaske et al., 2016) and 0.36 to $1.13 \mathrm{~s}^{-1}$ (Kurt et al., 2016). The differences with $\mathrm{k}_{\mathrm{L}}$ a values of the present work are likely due to the differences in the systems, channel dimensions and the operating conditions. The $\mathrm{k}_{\mathrm{L}}$ a values observed, however, are higher than typical values reported for conventional contactors -- $(0.2$ to $20) \times 10^{-4} \mathrm{~s}^{-1}$ in agitated vessels, $(5$ to 110$) \times 10^{-4} \mathrm{~s}^{-1}$ in packed columns, $28 \times 10^{-4} \mathrm{~s}^{-1}$ in spray column (Kashid et al., 2007).

\section{CONCLUSIONS}

Liquid-liquid extraction studies for the separation of aromatics from alkanes using polar solvents were conducted for three systems in three capillaries. Extraction efficiencies were obtained for all the systems. Extraction efficiencies ranging from 46.3 $\%$ to $97.3 \%$ were obtained, depending upon the combination of the flow velocity, residence time and channel diameter. Thus extraction efficiencies for the $<2 \mathrm{~mm}$ diameter capillaries, as well as the $2 \mathrm{~mm}$ capillary (when the residence time is $>0.78 \mathrm{~min}$ ), are greater than $80 \%$. The $90 \%$ or greater efficiency cases indicate that mass transfer rate may not be that much of an issue. The usual difficulties of microprocessing --fabrication, maintenance and cost, are more likely to decide its use rather than the extraction process itself. The cases where efficiencies are low (46 to $68 \%$ ) are the ones with low velocities, low residence times and larger channel diameter. It was also seen that as the liquids come out of the channel the separation into two clear phases (layers) is very fast. Partly this is due to the slug flow in the channel where the two phases are already separate. This quick phase separation could be a time saving factor in actual operation.

The effect of single parameters on extraction efficiency was also isolated from the various combinations. Efficiency increased from 68 to $83 \%$ as 


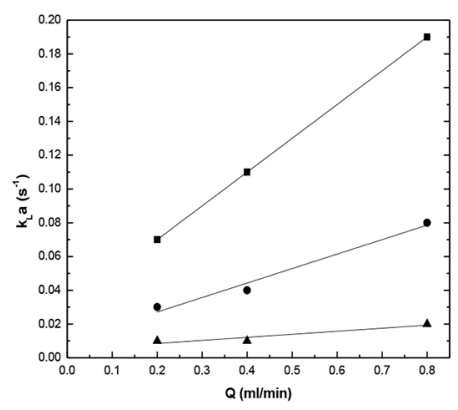

(a)

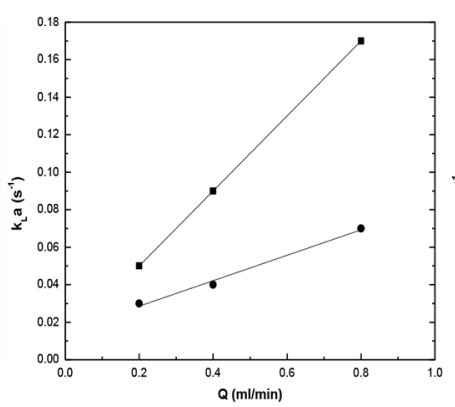

(b)

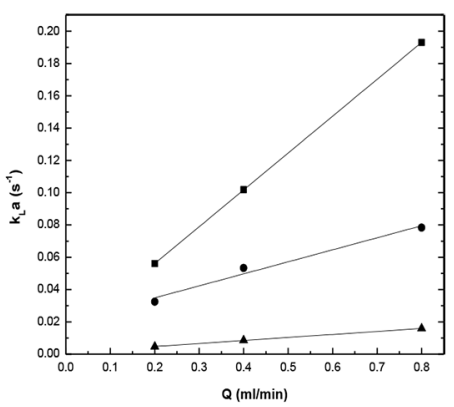

(c)

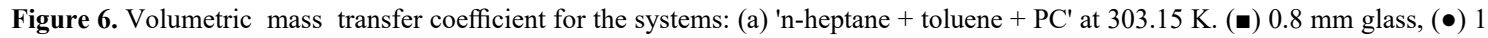
mm PTFE and ( $\boldsymbol{\Delta}) 2 \mathrm{~mm}$ glass capillary; (b) 'n-heptane + toluene + furfural' at $303.15 \mathrm{~K}$. (•) $0.8 \mathrm{~mm}$ glass and $(\bullet) 1 \mathrm{~mm}$ PTFE

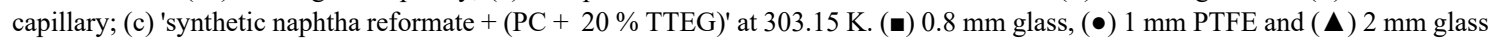
capillary.

flow velocity increased from 0.11 to $0.96 \mathrm{~cm} / \mathrm{s}$ while residence time and channel diameter remained fixed at $0.78 \mathrm{~min}$ and $2 \mathrm{~mm}$ respectively. Likewise, efficiency was seen to increase with residence time but decrease with diameter while the other two parameters were held constant. This is in keeping with the expected physical behavior of the phenomena.

Volumetric mass transfer coefficients $\left(\mathrm{k}_{\mathrm{L}} \mathrm{a}\right)$ determined for the three systems were in the range of 0.005 to $0.20 \mathrm{~s}^{-1}$. These are of comparable magnitude to the $\mathrm{k}_{\mathrm{L}}$ a values from other reported slug flow extraction data, such as for the system 'water + succinic acid + n-butanol' and 'water + iodine + kerosene', and higher than the values for conventional contactors.

\section{REFERENCES}

Antony, R., Nandagopal, M.S.G., Sreekumar, N., Rangabhashiyam, S., Selvaraju, N. Liquid-liquid Slug Flow in a Microchannel Reactor and its Mass Transfer Properties - A Review, Bulletin of Chem. Reaction Eng. \& Cat., 9, 207-223 (2014).

Assmann, N., von Rohr, P.R., Extraction in microreactors: Intensification by adding an inert gas phase, Chem. Eng. Process., 50, 822-827 (2011).

Burns, J. R., Ramshaw, C., The intensification of rapid reactions in multiphase systems using slug flow in capillaries, Lab on a Chip, 1, 10-15 (2001).

Dessimoz, A.-L., Cavin, L., Renken, A., KiwiMinsker, L., Liquid-liquid two-phase flow patterns and mass transfer characteristics in rectangular glass microreactors, Chem. Eng. Sci., 63, 4035 4044 (2008).

Jovanovic, J., Zhou, W., Rebrov, E. V., Nijhuis, T.A., Hessel, V., Schouten, J.C., Liquid-liquid slug flow: Hydrodynamics and pressure drop, Chem. Eng. Sci., 66, 42-54 (2011).
Kamio, E., Seike, Y., Yoshizawa, H., Matsuyama, H., Ono, T., Microfluidic Extraction of Docosahexaenoic Acid Ethyl Ester: Comparison between Slug Flow and Emulsion, Ind. Eng. Chem. Res., 50, 6915-6924 (2011).

Kashid, M. N., Harshe, Y. M., Agar, D. W., LiquidLiquid Slug Flow in a Capillary: An Alternative to Suspended Drop or Film Contactors, Ind. Eng. Chem. Res., 46, 8420-8430 (2007).

Kashid, M. N., Renken, A., Kiwi-Minsker, L., Gas-liquid and liquid-liquid mass transfer in microstructured reactors, Chem. Eng. Sci., 66, 3876-3897 (2011).

Kaske, F., Dick, S., Pajoohi, S.A., Agar, D.W., The influence of operating conditions on the mass transfer performance of a micro capillary contactor with liquid-liquid slug flow, Chem. Eng. Process., 108, 10-16 (2016).

Kurt, S.K., Gürsel, I.V., Hessel, V., Nigam, K.D.P., Kockmann, N., Liquid-liquid extraction system with microstructured coiled flow inverter and other capillary setups for single-stage extraction applications, Chem. Eng. J., 284, 764-777 (2016).

Liu, G., Wang, K., Lu, Y., Luo, G., Liquid-liquid microflows and mass transfer performance in slitlike microchannels, Chem. Eng. J., 258, 34-42 (2014).

Okubo, Y., Maki, T., Aoki, N., Khoo, T. H., Ohmukai, Y., Mae, K., Liquid-liquid extraction for efficient synthesis and separation by utilizing microspaces, Chem. Eng. Sci., 63, 4070-4077 (2008).

Raimondi, N. D. M., Prat, L., Gourdon, C., Tasselli, J. Experiments of mass transfer with liquid-liquid slug flow in square micro-channels, Chem. Eng. Sci., 105, 169-178 (2014). 
Saha, M., Rawat, B. S., Khanna, M. K., Nautiyal, B. R. Liquid-Liquid Equilibrium Studies on Toluene + Heptane +Solvent, J. Chem. Eng. Data, 43, 422426 (1998).

Salem, A. B. S. H., Liquid-liquid equilibria for the systems triethylene glycol- toluene-heptane, propylene carbonate-toluene-heptane and propylene carbonate-o-xylene-heptane, Fluid Phase Equilib., 86, 351-361 (1993).

Somekh, G. S.; Friedlander, B. O. Tetraethylene Glycol-A superior Solvent for Aromatics Extraction. Adv. Chem. Ser., 97, 228- 241 (1970).

Su, Y., Zhao. Y., Chen, G., Yuan, Q., Liquid-liquid two-phase flow and mass transfer characteristics in packed microchannels, Chem. Eng. Sci., 65, 39473956 (2010).

Tang, J. Zhang, X, Cai, W., Wang, F., Liquid-liquid extraction based on droplet flow in a vertical microchannel, Exp. Thermal and Fluid Sci., 49, 185-192 (2013).

Tsaoulidis, D., Angeli, P., Effect of channel size on mass transfer during liquid-liquid plug flow in small scale extractors, Chem. Eng. J., 262, 785-793 (2015).

Xu, B., Cai, W., Liu, X., Zhang, X., Mass transfer behavior in liquid-liquid slug flow in circular crosssection microchannel, Chem. Eng. Res. Des., 91, 1203-1211 (2013).

Zhao, Y., Chen, G., Yuan, Q., Liquid-Liquid Two-Phase Mass Transfer in the T-Junction Microchannels, AIChE J., 53, 3042-3053 (2007)

Woitalka, A., Kuhn, S., Jensen, K.F., Scalability of mass transfer in liquid-liquid flow, Chem. Eng. Sci., 116, 1-8 (2014). 